\title{
The effect of birth weight on the variation in live weight of pigs at weaning
}

\section{J. Allen ${ }^{1,2}$, E. Magowan ${ }^{1}$, V.E. Beattie ${ }^{2}$, M.E.E. McCann ${ }^{1}$, A. Thompson ${ }^{3}$}

${ }^{1}$ Agri-Food and Biosciences Institute, Hillsborough, United Kingdom, ${ }^{2}$ Devenish Nutrition Ltd, Belfast, United Kingdom,

${ }^{3}$ John Thompson and Sons Ltd, Belfast, United Kingdom

Email: elizabeth.magowan@afbini.gov.uk

Introduction A high variation in birth weight has been found to contribute to high variations in survivability (Akdag et al. 2009). However, few studies have determined the effect of birth weight on variation in wean weight. Using the historical records of the research herd at AFBI Hillsborough, which include the birth and wean weight of all pigs born, the objective of this study was to investigate the effect of birth weight on the variability in pig wean weight.

Materials and methods Data from 96 batches of farrowings, (on average 14 sows farrowed per batch giving 1,351 sows in total) which took place between January 2003 and April 2008 on the AFBI Hillsborough herd, were used. On average, each sow had 3.9 farrowings and the average number of pigs weaned per sow was 9.7. All pigs born (13,158) were Landrace $x$ Large White and were weighed within 2 hours of birth, and again at weaning (28 days +/- 2 days). The coefficient of variation (CV) for birth and wean weight of the pigs reared within each batch of farrowing was calculated and analysis of variance was used to test for differences. Regression analysis investigated the relationship between birth weight and 28 day weight. Furthermore, the data were grouped into weight categories: $0.75 \mathrm{~kg}(120 \mathrm{pigs}), 1.00 \mathrm{~kg}(486$ pigs), $1.25 \mathrm{~kg}$ (1,458 pigs), $1.50 \mathrm{~kg}$ (1,878 pigs), $1.75 \mathrm{~kg}$ (1,824 pigs), $2.00 \mathrm{~kg}$ (786 pigs), and $2.25 \mathrm{~kg}(294 \mathrm{pigs})$ with a tolerance of $+/-0.05 \mathrm{~kg}$ within each weight category. Within each weight category, the data were randomised into 6 groups which represented 6 replicates. For each 'replicate' within each weight category, the coefficient of variation (CV), standard deviation (SD) and average of the 28 day weight was calculated, and then regressed against birth weight. The effect of birth weight category on average wean weight, SD and CV of wean weight were analysed by Analysis of Variance. Using the same weight categories described above, the probability of pigs being above $8 \mathrm{~kg}, 8.5 \mathrm{~kg}$ or $9 \mathrm{~kg}$ at weaning was calculated.

Results The CV of wean weight (0.18) (representative of all pigs born within a batch of farrowings) was found to be significantly lower $(\mathrm{P}<0.001)$ than the $\mathrm{CV}$ of birth weight $(0.21)$. The relationship between birth weight and 28 day weight was found to be significant $(\mathrm{P}<0.001)$ but weak $\left(\mathrm{R}^{2}=0.243\right)$. As birth weight increased, wean weight also increased $(\mathrm{P}<0.001)$ (Table 1). Birth weight had a significant effect on the SD and CV of wean weight (both $\mathrm{P}<0.001)($ Table 1$)$. In general as the birth weight of pigs increased the SD and CV for their wean weight decreased. The relationship between birth weight and the CV of wean weight was found to be strong $\left(\mathrm{R}^{2}=0.927\right)$ and fitted an inverse quadratic curve (Figure 1). It was also found that a pig with a birth weight under $1 \mathrm{~kg}$ at birth had a $28 \%$ probability of being over $8 \mathrm{~kg}$ at weaning, compared with a $64 \%$ probability for a pig with a birth weight between 1 and $1.5 \mathrm{~kg}$ (Table 2).

Table 1 The effect of birth weight on the average, SD and CV of wean weight

\begin{tabular}{llllllllll}
\hline \hline & $0.75 \mathrm{~kg}$ & $1.00 \mathrm{~kg}$ & $1.25 \mathrm{~kg}$ & $1.50 \mathrm{~kg}$ & $1.75 \mathrm{~kg}$ & $2.00 \mathrm{~kg}$ & $2.25 \mathrm{~kg}$ & LSD & P \\
\hline Average $(\mathrm{kg})$ & $6.82^{\mathrm{a}}$ & $7.72^{\mathrm{b}}$ & $8.3^{\mathrm{c}}$ & $9.08^{\mathrm{d}}$ & $9.6^{\mathrm{e}}$ & $10.25^{\mathrm{f}}$ & $10.7^{\mathrm{g}}$ & 0.05 & $<0.001$ \\
SD & $1.71^{\mathrm{a}}$ & $1.58^{\mathrm{b}}$ & $1.5^{\mathrm{bc}}$ & $1.54^{\mathrm{bc}}$ & $1.46^{\mathrm{c}}$ & $1.46^{\mathrm{c}}$ & $1.52^{\mathrm{bc}}$ & 0.10 & $<0.001$ \\
$\mathrm{CV}$ & $0.250^{\mathrm{a}}$ & $0.205^{\mathrm{b}}$ & $0.181^{\mathrm{c}}$ & $0.170^{\mathrm{d}}$ & $0.152^{\mathrm{e}}$ & $0.143^{\mathrm{f}}$ & $0.142^{\mathrm{f}}$ & 0.0012 & $<0.001$ \\
\hline \hline
\end{tabular}

${ }^{\mathrm{a}, \mathrm{b}, \mathrm{c},}$ numbers with the same superscripts are not significantly different $(\mathrm{P}>0.05)$

Table 2 Probability (\%) of being over $8.0,8.5$ or $9.0 \mathrm{~kg}$ when born at different birth weights

\begin{tabular}{llll}
\hline \multirow{2}{*}{ Weight at birth: } & \multicolumn{3}{l}{ Weight at weaning: } \\
\cline { 2 - 4 }$<1 \mathrm{~kg}$ & $>8.0 \mathrm{~kg}$ & $>8.5 \mathrm{~kg}$ & $>9.0 \mathrm{~kg}$ \\
\cline { 2 - 4 } $1.0-1.5 \mathrm{~kg}$ & 28.0 & 18.3 & 11.8 \\
$1.5-2.0 \mathrm{~kg}$ & 64.1 & 51.3 & 37.0 \\
$>2 \mathrm{~kg}$ & 85.6 & 76.4 & 66.0 \\
\hline \hline
\end{tabular}

Conclusion This study highlighted that as birth weight increased, variable weight of pigs at weaning decreased. This suggests that light birth weight pigs are 'less predictable' in terms of weaning weight than heavier pigs. This is further highlighted

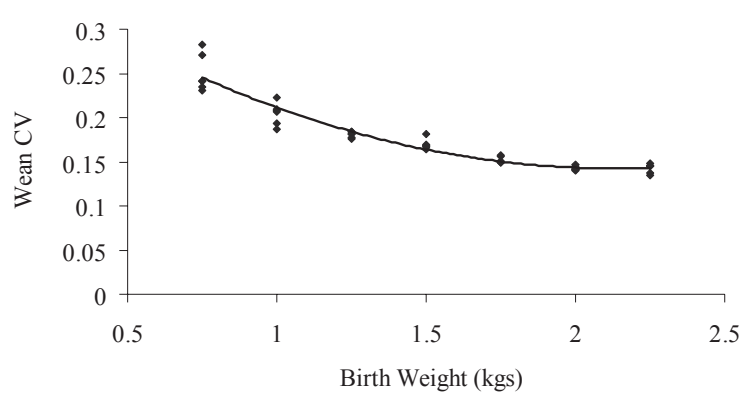

Figure 1 Relationship between birth weight and wean CV by $28 \%$ of pigs born under $1 \mathrm{~kg}$ achieving weaning weights over $8 \mathrm{~kg}$. However, this probability is based on an average litter size of 9.7. Competition for resources, e.g. milk, in larger litters would be greater and it would be of interest to investigate the effect of litter size on the above probability. Unfortunately it was not within the scope of this study to investigate the characteristics of the light birth weight pigs which were over $8 \mathrm{~kg}$ at wean, however these results suggest that light weight pigs at birth could be encouraged through managerial practices to achieve better weaning weights.

Acknowledgements The authors gratefully acknowledge funding from Devenish Nutrition Ltd.

Reference Akdag, F., Arslan, S. and Demir, H. 2009. Journal of Animal and Veterinary Advances 8, $2133-2138$. 